\title{
Association between modifiable lifestyle factors and inflammatory markers in patients with metabolic syndrome
}

M. Golzarand, ${ }^{7}$ K. Toolabi, ${ }^{2}$ M. Ebrahimi-Mameghani, ${ }^{1}$ A. Aliasgarzadeh ${ }^{3}$ and S. Arefhosseini ${ }^{1}$

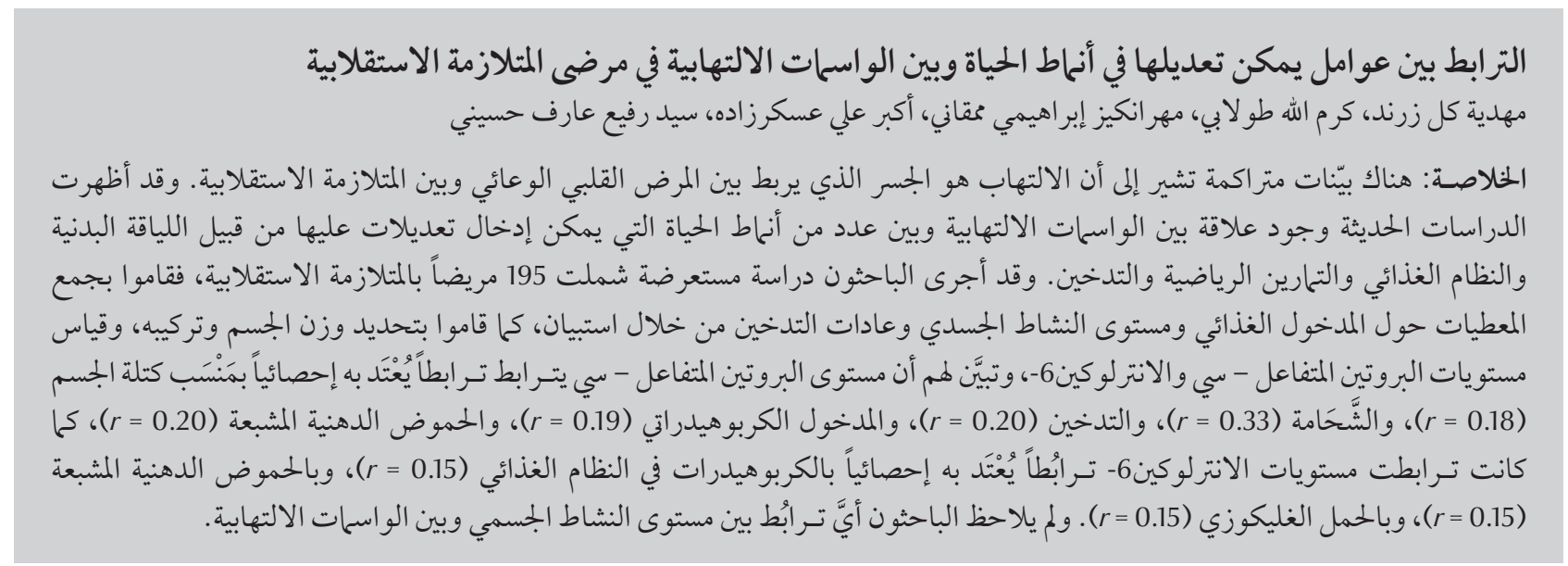

ABSTRACT There is accumulating evidence suggesting that inflammation is the bridging link between cardiovascular disease and metabolic syndrome. Recent studies have shown a relationship between inflammatory markers and modifiable lifestyle factors including fitness, diet, exercise and smoking. We carried out a cross-sectional study of 195 patients with metabolic syndrome. Data on nutritional intake, physical activity level and smoking habits were collected through a questionnaire. Weight and body composition were determined and C-reactive protein and interluekin-6 concentrations were measured. C-reactive protein level had a significant association with body mass index $(r=0.18)$, adiposity $(r=0.23)$, smoking $(r=0.20)$, carbohydrate intake $(r=0.19)$ and saturated fatty acid $(r=0.20)$. Interluekin-6 concentration was significantly correlated with dietary carbohydrate $(r=0.15)$, saturated fatty acid $(r=0.15)$ and glycaemic load $(r=0.15)$. No association was observed between physical activity level and inflammatory markers.

Association entre les facteurs modifiables liés au mode de vie et les marqueurs inflammatoires chez les patients atteints du syndrome métabolique

RÉSUMÉ Des preuves toujours plus nombreuses semblent indiquer que l'inflammation serait un lien entre les maladies cardio-vasculaires et le syndrome métabolique. Des études récentes ont démontré qu'une relation existait entre les marqueurs inflammatoires et les facteurs de mode de vie modifiables, notamment la forme physique, l'alimentation, l'activité physique et le tabagisme. Nous avons mené une étude transversale sur 195 patients atteints du syndrome métabolique. Des données sur les apports alimentaires, le niveau d'activité physique et les habitudes de consommation de tabac ont été recueillies au moyen d'un questionnaire. Le poids et la taille ont été mesurés et les taux de protéine C-réactive et d'interleukine-6 ont été analysés. Le taux de protéine C-réactive était fortement associé à l'indice de masse corporelle $(r=0,18)$, l'adiposité $(r=0,23)$, au tabagisme $(r=0,20)$, à l'apport glucidique $(r=0,19)$ et aux acides gras saturés $(r=0,20)$. Il y avait une corrélation significative entre le taux d'interleukine-6 et la prise de glucides $(r=0,15)$, d'acides gras saturés $(r=0,15)$ et la glycémie $(r=0,15)$. Dans la présente étude, aucune association n'a été observée entre le niveau d'activité physique et les marqueurs inflammatoires.

${ }^{7}$ Nutritional Research Centre, Faculty of Health and Nutrition; ${ }^{3}$ Department of Endocrinology, Imam Reza Hospital, Tabriz University of Medical Sciences, Tabriz, Islamic Republic of Iran. ${ }^{2}$ Department of Surgery, Imam Khomeini Hospital, Tehran University of Medical Sciences, Tehran, Islamic Republic of Iran. (Correspondence to K. Toolabi: tolabika@tums.ac.ir).

Received: 12/04/10; accepted: 28/11/10 


\section{Introduction}

Metabolic syndrome is a clustering of metabolic disorders including dyslipidaemia, glucose and insulin metabolism disorders, obesity (abdominal obesity) and hypertension, all of which are associated with cardiovascular disease (CVD) [1]. Inflammation is one of the features of metabolic syndrome, which originates from excess visceral adipose tissue [2]. Elevated levels of inflammatory markers are associated with atherosclerosis, and C-reactive protein (CRP) is one of the most sensitive indicators of systemic inflammation [3]. CRP concentration is primarily derived via interleukin-6 (IL-6)-dependent hepatic biosynthesis. IL-6, a major proinflammatory cytokine, is produced in a variety of tissues, including activated leukocytes, adipocytes, and endothelial cells [4].

Epidemiological and cross-sectional investigations have demonstrated a strong correlation between inflammatory markers and hyperinsulinaemia, hypertriglyceridaemia, low high-density lipoprotein (HDL)-cholesterol, body mass index (BMI), hypertension, age, and elevated fibrinogen and plasminogen activator inhibitor- 1 concentrations $[3,5]$. Several of the drugs used to treat hyperglycaemia and dyslipdaemia can reduce concentrations of inflammatory markers [1]. Recently, some studies have shown inflammatory markers are associated with lifestyle factors including diet, adipose tissue, physical activity and cigarette smoking $[6,7]$ and have suggested lifestyle modification may reduce the risk of inflammation and CVD [8]. Accordingly, this study was aimed at investigating the association between modifiable lifestyle factors with inflammatory markers in patients with metabolic syndrome in order to gain a better understanding of the factors that cause this phenomenon and prevention of CVD in these individuals.

\section{Methods}

\section{Participants}

This was a cross-sectional study. Participants were selected by non-random, sequential sampling from the all patients with metabolic syndrome who were referred to the Endocrinology Clinic of Sina Hospital, Tabriz from April 2007 to April 2008. Diagnosis of metabolic syndrome was based on World Health Organization (WHO) criteria [9]: type II diabetes, impaired fasting glucose or insulin resistance plus $\geq 2$ of the following: $\mathrm{BMI}>30 \mathrm{~kg} / \mathrm{m}^{2}$, triglycerides $\geq 150$ $\mathrm{mg} / \mathrm{dL}, \mathrm{HDL}<35 \mathrm{mg} / \mathrm{dL}$ (men) and $39 \mathrm{mg} / \mathrm{dL}$ (women), blood pressure (systolic/diastolic) $>140 / 90 \mathrm{mmHg}$ and microalbuminuria $>20 \mu \mathrm{g} / \mathrm{min}$. Exclusion criteria were: pregnancy or lactation; cancer; inflammatory, hepatic or renal disease; and insulin therapy.

After selection, eligible patients were invited to the Endocrinology Clinic of Sina Hospital and the aim of study was explained to them. Two weeks later between June and July 2008, patients who agreed to participate in the study were visited at the same clinic and information on lifestyle factors was collected and blood samples were taken.

From the 291 patients who were eligible for inclusion in the study, 195 agreed to participate. The 96 who refused did so mainly due to their unwillingness to participate.

The study protocol was approved by the Ethics Committee at the Tabriz University of Medical Sciences, and informed consent was obtained from all participants.

\section{Assessments}

At the second visit, subjects were interviewed face to face by a trained interviewer using a questionnaire. Physical activity was assessed using a questionnaire from Dixon et al. [10]. Participants who performed physical exercise at least 5 times a week for a minimum of 30 minutes were considered physically active. The design of the smoking questionnaire was based on data obtained from the research of Ohsawa et al. [11]. Those who smoked daily or had stopped smoking for $<5$ years were classed as smokers; non-smokers included those who had never smoked and those who had not smoked for $\geq 5$ years. Nutritional intake data were collected using a 24-hour dietary recall for 3 days (2 workdays and 1 holiday) by a trained nutritionist and analysed using Nutrition III software. At the same time, weight was measured using a scale (Seca, Germany) and height was measured using a tape and BMI was calculated as weight $/$ height ${ }^{2}\left(\mathrm{~kg} / \mathrm{m}^{2}\right)$. Those who had BMI $<30 \mathrm{~kg} / \mathrm{m}^{2}$ were defined as non-obese and the rest of them were defined as obese. Body composition was measured using a bioelectric impedance device (TANITA Model TBF-215, Germany). To avoid interinvestigator error, all questionnaires and measurements were obtained by the same person.

Blood samples for measurement of CRP and IL-6 were obtained between 8 am and $11 \mathrm{am}$. Sampleswere centrifuged at $2000 \mathrm{~g}$ for $15 \mathrm{~min}$ and serum samples were stored at $-60^{\circ} \mathrm{C}$ until assay. CRP concentration was determined by highsensitivity immunoturbidimetric assay using an auto-analyser (model Alcyon 300 Abbott, USA and Germany) and IL-6 concentration was determined by enzyme-linked immunosorbent assay (ELISA) (STAT FAX, United States of America) at the Drug Applied Research Centre Laboratory of Tabriz University of Medical Sciences.

\section{Statistical analysis}

Statistical analysis was performed using SPSS software, version 11.5. Variables were tested for normality using histograms and the Kolmogorov-Smirnov test. Data were presented as mean and standard deviation (SD). Association between inflammatory markers and continuous variables (diet composition and anthropometric indices) and 
non-continuous variables (smoking habits and physical activity) were tested with linear regression models and chi-squared test, respectively. The difference in CRP and IL-6 concentrations among groups was analysed using independent-sample $t$-test. The level of significance was defined at $P<0.05$.

\section{Results}

The study population included $30.8 \%$ men and $69.2 \%$ women. Table 1 summarizes the general characteristics of the participants. There were no significant differences in general characteristics (except height) between men and women. The assay showed that $24.6 \%$ of participants were in pro-inflammatory status $(\mathrm{CRP}>3 \mathrm{mg} / \mathrm{L})$.

Table 2 shows the modifiable lifestyle factors in the study subjects. Women had significantly higher BMI and adiposity compared to men $(P<$ 0.0001 for both). Men had significantly higher levels of physical activity $(P<$ $0.05)$ and cigarette smoking habit $(P<$ $0.01)$. There were no significant differences in diet composition.

Figure 1 shows the levels of CRP and IL- 6 in obese and non-obese participants, smokers and non-smokers and active and inactive subjects. CRP concentration was statistically significantly higher in obese than non-obese participants $[2.6$ (SD 2.3$) \mathrm{mg} / \mathrm{L}$ vs 1.6 (SD 1.5) $\mathrm{mg} / \mathrm{L}]$ and in smokers than non-smokers [2.3 (SD 2.1) mg/L vs 1.2 (SD 1.0) $\mathrm{mg} / \mathrm{L}]$. There were no significant differences in IL-6 concentration for these groups of participants.

Table 3 shows relationships between inflammatory markers and lifestyle factors. BMI $(P<0.05)$, fat mass $(P$ $<0.01)$ and body fat $(P<0.001)$ were significantly associated with CRP level. There were also statistically significant associations between CRP concentration and dietary intake of carbohydrate $(P<0.01)$ and saturated fatty acids $(P<$ $0.01)$. Similar trends were seen between IL-6 level and dietary intake of carbohydrate $(P<0.05)$, saturated fatty acids $(P$ $<0.05)$ and glycaemic load $(\mathrm{GL})(P<$ $0.05)$. There were inverse associations between CRP level and dietary intake of monounsaturated fatty acids and polyunsaturated fatty acids, but these were not statistically significant. No relationship was observed between CRP concentration or IL-6 concentration and dietary fat, protein and glycaemic index (GI). CRP level, but not IL-6 level, was statistically significantly associated with cigarette smoking $(P<0.05)$.

\section{Discussion}

Our study was conducted to assess association of inflammatory markers and modifiable lifestyle factors. As expected, CRP level had a positive correlation with adiposity, a finding confirmed by others $[12,13]$. Ruiz et al. [13] showed that adipose tissue has the greatest influence on CRP concentration. Adipose tissue is a source of pro-inflammatory cytokines such as tumour necrosis factor- $\alpha$ (TNF- $\alpha$ ) and IL-6 [14]. Approximately $25 \%$ of basal circulating IL-6 is produced by adipose tissue especially intra-abdominal fat. IL-6 is the main regulator of synthesis of CRP by the liver. Van Ree et al. showed that CRP mRNA, is also expressed in human subcutaneous abdominal adipose tissue. These findings suggest adipose tissue as an important determinant of basal CRP levels [15].

Significant associations between dietary carbohydrate and saturated fatty acid intake and CRP and IL- 6 concentrations were observed in the present study. Our findings suggested that

\begin{tabular}{|c|c|c|c|c|}
\hline Characteristic & $\begin{array}{c}\text { Total } \\
\text { Mean (SD) }\end{array}$ & $\begin{array}{c}\text { Men } \\
\text { Mean (SD) }\end{array}$ & $\begin{array}{c}\text { Women } \\
\text { Mean (SD) }\end{array}$ & $P$ \\
\hline Age (years) & $56.0(11.7)$ & 59.2 (13.9) & $54.6(10.7)$ & 0.08 \\
\hline Weight (kg) & 76.5 (12.2) & 77.9 (14.6) & 76.3 (11.0) & 0.38 \\
\hline Height $(\mathrm{cm})$ & $159.0(8.0)$ & $167.0(6.9)$ & $155.4(5.4)$ & $<0.001$ \\
\hline FBS (mg/dL) & $181.4(75.6)$ & $172.3(64.6)$ & $185.6(79.4)$ & 0.25 \\
\hline $\mathrm{TC}(\mathrm{mg} / \mathrm{dL})$ & $203.8(69.0)$ & $196.2(30.7)$ & $207.8(79.0)$ & 0.34 \\
\hline $\mathrm{HDL}-\mathrm{C}(\mathrm{mg} / \mathrm{dL})$ & $45.2(16.7)$ & $42.5(13.6)$ & $46.4(17.0)$ & 0.42 \\
\hline LDL-C (mg/dL) & $103.3(43.5)$ & 101.0 (32.8) & $104.4(47.8)$ & 0.61 \\
\hline $\mathrm{TG}(\mathrm{mg} / \mathrm{dL})$ & 260.7 (182.3) & $233.4(140.6)$ & $273.1(196.3)$ & 0.16 \\
\hline $\mathrm{SBP}(\mathrm{mmHg})$ & $153.2(19.7)$ & 151.6 (17.9) & $154.3(20.3)$ & 0.38 \\
\hline $\mathrm{DBP}(\mathrm{mmHg})$ & 89.9 (13.7) & $88.9(10.2)$ & $90.4(15.0)$ & 0.48 \\
\hline CRP (mg/L) & $2.1(2.0)$ & $1.9(1.8)$ & $2.5(2.2)$ & 0.07 \\
\hline IL-6 (pg/mL) & $3.5(3.7)$ & $3.6(3.2)$ & $3.4(3.3)$ & 0.83 \\
\hline
\end{tabular}

FBS = fasting blood sugar; $T C=$ total cholesterol; $H D L-C=$ high density lipoprotein-cholesterol; $L D L-C=$ low density lipoprotein-cholesterol; $T G=$ triglyceride; $S B P=$ systolic blood pressure; $D B P=$ diastolic blood pressure, $C R P=C$-reactive protein; $I L-6=$ interleukin- 6 . $S D=$ standard deviation. 


\begin{tabular}{|c|c|c|c|c|}
\hline \multirow[t]{2}{*}{ Modifiable lifestyle factor } & Total & Men & Women & $P$ \\
\hline & Mean (SD) & Mean (SD) & Mean (SD) & \\
\hline $\mathrm{BMI}\left(\mathrm{kg} / \mathrm{m}^{2}\right)$ & $30.4(4.8)$ & $27.9(4.9)$ & $31.5(4.3)$ & $<0.001$ \\
\hline Fat mass (kg) & $26.8(9.7)$ & $20.4(11.2)$ & $29.6(7.5)$ & $<0.001$ \\
\hline Body fat (\%) & $34.2(9.1)$ & $25.1(10.0)$ & $38.2(4.7)$ & $<0.001$ \\
\hline Carbohydrate (g) & $204.4(112.0)$ & $203.7(56.5)$ & 204.8 (101.8) & 0.94 \\
\hline Protein (g) & $59.9(27.8)$ & $61.3(25.5)$ & $59.3(28.8)$ & 0.65 \\
\hline Fat (g) & $77.3(25.6)$ & $82.5(26.5)$ & $74.9(24.9)$ & 0.06 \\
\hline SFA (g) & $16.8(6.6)$ & $18.8(6.8)$ & $15.9(7.3)$ & 0.08 \\
\hline MUFA (g) & $24.9(9.9)$ & 26.9 (11.8) & $24.1(8.8)$ & 0.10 \\
\hline PUFA (g) & $19.6(9.1)$ & $21.3(10.6)$ & $18.9(8.3)$ & 0.12 \\
\hline Fibre (g) & $6.7(5.6)$ & $7.2(6.1)$ & $6.5(5.3)$ & 0.42 \\
\hline Glycaemic index (\%) & $59.6(12.5)$ & $56.3(21.0)$ & $61.1(4.9)$ & 0.08 \\
\hline \multirow[t]{2}{*}{ Glycaemic load (g) } & 112.5 (79.6) & $116.4(34.8)$ & $103.5(67.9)$ & 0.06 \\
\hline & $\%$ & $\%$ & $\%$ & \\
\hline Smoker & 23.1 & 28.9 & 10.0 & 0.001 \\
\hline Non-smoker & 76.9 & 71.1 & 90.0 & 0.001 \\
\hline Physically active & 7.7 & 15.0 & 4.4 & 0.03 \\
\hline Not physically active & 92.3 & 85.0 & 95.6 & 0.03 \\
\hline
\end{tabular}

$B M I=$ body mass index $;$ SFA = saturated fatty acid; $M U F A=$ monounsaturated fatty acid; $P U F A=$ polyunsaturated fatty acid. $S D=$ standard deviation .

dietary composition might influence inflammatory markers. Several investigations have compared the effect of dietary carbohydrate on concentration of inflammatory markers. One study found no association between diet compositions and serum CRP [6]; another found that a low-carbohydrate diet increased serum CRP [16]. In a third study, the effect of low-carbohydrate diet on CRP concentration was consistent with our own observations [17]. Low-carbohydrate diets are high in fat and low in dietary antioxidants, which may increase susceptibility to oxidative stress and this would subsequently increase inflammation [16]. Nevertheless, the increase in CRP and IL-6 levels with high-carbohydrate diets may be a result of low fibre intake. In the present study, dietary fibre intake was very low, however, no significant association with anti-inflammatory markers was found. Some previous studies have, however, shown that high fibre diets can decrease inflammatory markers $[18,19]$.
Another possible reason for an increase in inflammatory markers with high-carbohydrate diets could be that such diets have high GI and high GL. Our findings have shown that IL-6 has significant positive association with a high GL diet. This finding is supported by a previous study which demonstrated that diets with high GI and high GL can cause a rise in inflammatory indicators [20]. Consumption of high GI diets was associated with production of pro-inflammatory mediators and a reduction in anti-inflammatory markers, leading to activation of the inflammatory process.

Type of dietary fat can also influence plasma and tissue fatty acid composition which can modify inflammation process. Aeberli et al. [21] have shown high saturated fatty acid intakes induced rising plasma levels of free saturated fatty acids, especially palmitic acid lead to impairing glucose and lipid metabolism and inducing expression of proinflammatory cytokines in adipocytes, skeletal muscle cells, and endothelial cells. In vivo, palmitic acid correlates with IL-6 concentrations, independent of adipose tissue. It has been supposed that high saturated fatty acids intakes of may stimulate IL-6 secretion. Although the effects of dietary compositions on CRP levels have not been fully elucidated, epidemiological studies have shown diet high in fruits, vegetables, grains and fibre are associated with lower CRP levels while diets high in trans-fatty acids and high GL diets are associated with higher CRP levels [16]. Clinical trials are needed to confirm the effect of dietary manipulation on serum CRP.

In the present study, we found no association between CRP or IL-6 concentrations and physical activity. Previous findings that examined the relationship between exercise and inflammatory markers are controversial. Some have demonstrated the beneficial effects of exercise on inflammation [22,23], whereas others, consistent with the results of the present study, reported physical activity having no correlation with inflammatory markers $[24,25]$. A 

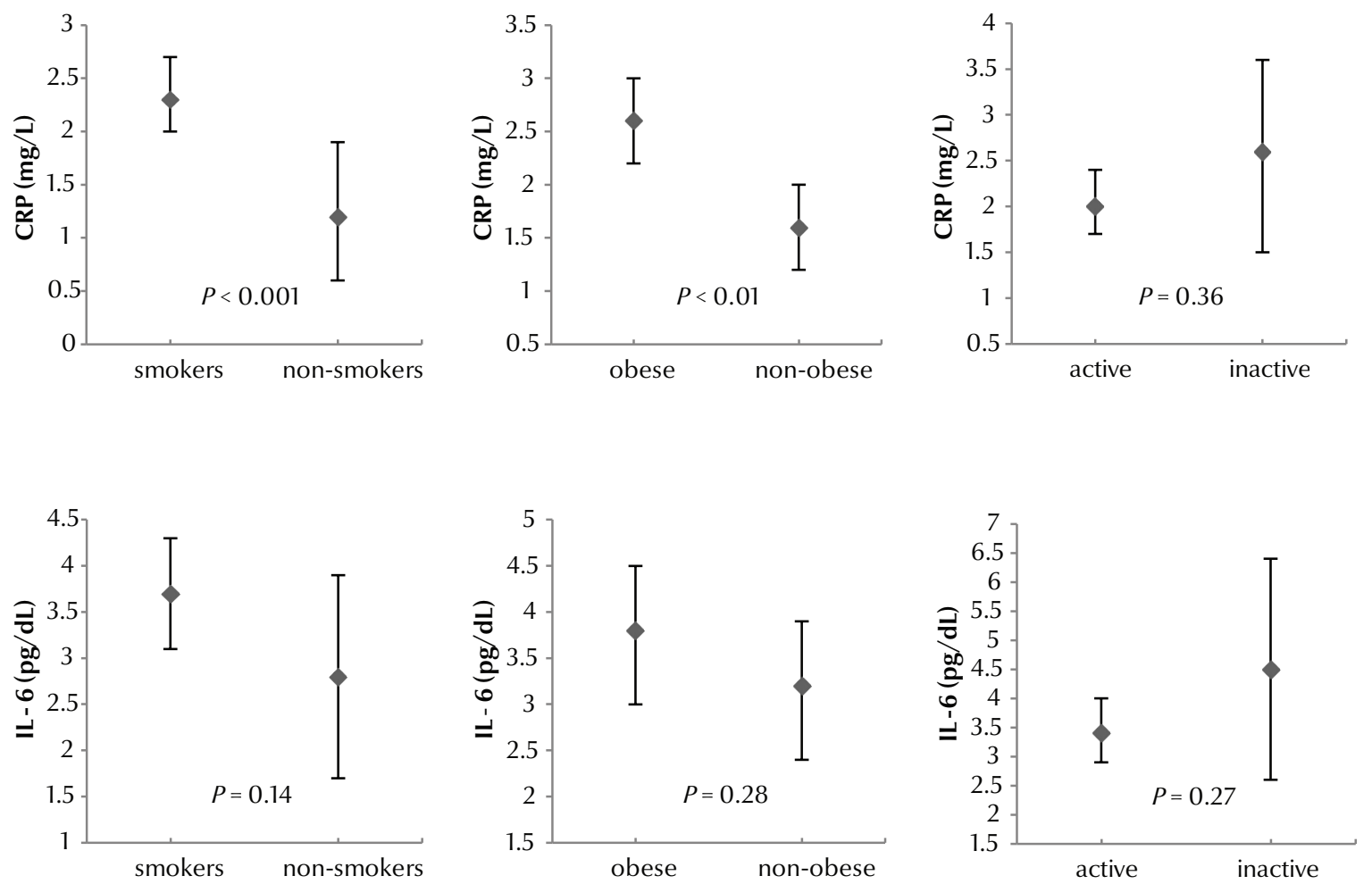

Figure 1 Mean C-reactive protein (CRP) and interleukin-6 (IL-6) levels according to obesity, smoking habits and physical activity

possible explanation for inconsistent association between physical activity and inflammatory markers is that physical questionnaire used was not sensitive enough in this respect. Recently, Balducci et al. [23] have shown $\mathrm{VO}_{2}$ max is a strong predictor of CRP level, independent of body weight. Accordingly, direct measurement of $\mathrm{VO}_{2}$ max in a laboratory may results in accurate value of aerobic fitness and lead to a different association with inflammatory marker

\begin{tabular}{lcccc}
\hline \multicolumn{5}{c}{ Table 3 Association between inflammatory markers and lifestyle factors } \\
\hline Lifestyle factor & C-reactive & protein & \multicolumn{2}{c}{ Interleukin-6 } \\
BMI & $\boldsymbol{r}$ & $\boldsymbol{P}$ & $\boldsymbol{r}$ & $\boldsymbol{P}$ \\
Fat mass & 0.18 & 0.011 & 0.02 & 0.659 \\
Body fat & 0.23 & 0.002 & 0.07 & 0.281 \\
Carbohydrate & 0.27 & 0.000 & 0.09 & 0.205 \\
Protein & 0.19 & 0.009 & 0.15 & 0.034 \\
Fat & 0.10 & 0.098 & 0.13 & 0.076 \\
SFA & 0.03 & 0.598 & -0.01 & 0.822 \\
MUFA & 0.20 & 0.005 & 0.15 & 0.034 \\
PUFA & -0.13 & 0.060 & -0.11 & 0.110 \\
Glycaemic index & -0.13 & 0.069 & -0.07 & 0.275 \\
Glycaemic load & 0.06 & 0.400 & 0.09 & 0.180 \\
Smoking & 0.11 & 0.133 & 0.15 & 0.030 \\
Physical activity & 0.20 & 0.000 & 0.06 & 0.640 \\
\hline
\end{tabular}

$B M I=$ body mass index $;$ SFA = saturated fatty acid; $M U F A=$ monounsaturated fatty acid; $P U F A=$ polyunsaturated fatty acid. concentrations. Therefore, further investigations are advisable.

We found a positive association between serum CRP and smoking. This is in agreement with the findings of previous studies [26-28]. Smoking is a major modifiable risk factor for CVD and by producing a state of inflammation promotes atherosclerosis. Several studies have assessed the mechanisms responsible for the positive relationship between smoking and elevated inflammatory indices: it has been shown smoking increases gene expression and serum concentration of IL-6 [26]. Elevated IL-6 level leads to raised CRP concentration and inflammation initiation. Another study reported that smoking causes release of interleukin-6 from visceral adipose tissue, which results in increased CRP production by hepatocytes [27]. However, in a related study it was suggested that cigarette smoking, via tissue damage, caused an inflammatory stimulus and increased CRP level [28]. In our study, we did not 
consider ex-smokers as a separate group due to the small numbers, so we could not assess the association between inflammatory marker levels and smoking cessation. However, other studies have shown smoking cessation reduces inflammatory markers but their levels do not fall to normal $[28,29]$. Therefore, our results reinforce the need to encourage smoking cessation as early as possible.

This study had several limitations. Because it was cross-sectional, the directionality of the reported associations could not be established. The sample size may not have been large enough to identify minor association between CRP and IL- 6 and lifestyle factors.
Besides this, the relatively low response rate may have affected the relationship between inflammatory markers and lifestyle factors. We used 24-hour dietary recall for assessment of nutritional intake. This relies on the participants' memory, and they may underestimate dietary intake. Therefore, it may affect the observed correlation between inflammatory markers and diet composition. Concurrent application of other dietary assessment tools such as food record with 24-hour dietary recall for correct estimation of dietary intake is important. The number of cigarettes smoked per day and duration of smoking were not considered. Inflammatory marker levels in ex-smokers were not evaluated. So it was not possible to conclude any associations between inflammatory markers and these lifestyle factors. Additionally, the use of a single fasting measurement of CRP and IL-6 may not necessarily reflect chronic inflammatory status.

\section{Acknowledgements}

This study was supported by the Nutrition Research Centre of Tabriz University of Medical Sciences. Our sincere thanks to the participants and the staff of the Endocrinology Clinic of Sina Hospital, in Tabriz, Islamic Republic of Iran.

\section{References}

1. Eckel RH, Grundy SM, Zimmet PZ. The metabolic syndrome. Lancet, 2005, 365(9468):1415-1428.

2. Elk CM, Francis J. Central adiposity, systemic inflammation, and the metabolic syndrome. Current Hypertension Reports, 2010, 12:99-104.

3. Steinberger $\mathrm{J}$ et al. Progress and challenges in metabolic syndrome in children and adolescents: a scientific statement from the American Heart Association Atherosclerosis, Council on Nutrition, Physical Activity, and Metabolism Cardiovascular Disease in the Young; Council on Cardiovascular Nursing; and Hypertension, and Obesity in the Young Committee of the Council on Nutrition, Physical Activity, and Metabolism. Circulation, 2009, 119:628-647.

4. Pradhan AD et al. C-reactive protein, Interleukin-6, and risk of developing type 2 diabetes mellitus. Journal of the American Medical Association, 2001, 286(3):327-334.

5. Cornier MA et al. The metabolic syndrome. Endocrine Reviews, 2008, 29:777-822.

6. Thomas NE et al. C-reactive protein in schoolchildren and its relation to adiposity, physical activity, aerobic fitness and habitual diet. British Journal of Sports Medicine, 2008, 42:357-360.

7. Hamer $\mathrm{M}$. The relative influences of fitness and fatness on inflammatory factors. Preventive Medicine, 2007, 44(1):3-11.

8. Ziegler D. Type 2 diabetes as an inflammatory cardiovascular disorder. Current Molecular Medicine, 2005, 5(3):309-322.

9. Alberti KG, Zimmet PZ. Definition, diagnosis and classification of diabetes mellitus and its complications. Part 1: diagnosis and classification of diabetes mellitus provisional report of a WHO consultation. Diabetic Medicine, 1998, 15(7): 539-553.

10. Dixon NC et al. Active middle-aged men have lower fasting inflammatory markers but the postprandial inflammatory response is minimal and unaffected by physical activity status. Journal of Applied Physiology, 2009, 107(1):63-68.

11. Ohsawa $\mathrm{M}$ et al. CRP levels are elevated in smokers but unrelated to the number of cigarettes and are decreased by longterm smoking cessation in male smokers. Preventive Medicine, 2005, 41(2):651-656.
12. Ortega Martinez de Victoria E et al. Macrophage content in subcutaneous adipose tissue associations with adiposity, age, inflammatory markers, and whole-body insulin action in healthy Pima Indians. Diabetes, 2009, 58(2):385-393.

13. Ruiz JR et al. Associations of low-grade inflammation with physical activity, fitness and fatness in prepubertal children: the European Youth Heart Study. International Journal of Obesity, 2007, 31(10):1545-1551.

14. Wisse BE. The inflammatory syndrome: the role of adipose tissue cytokines in metabolic disorders linked to obesity. Journal of the American Society of Nephrology, 2004, 15(11):2792-2800.

15. Van Ree RM et al. Abdominal obesity and smoking are important determinants of C-reactive protein in renal transplant recipients. Nephrology Dialysis Transplantation, 2005, 20(11):2524-2531.

16. Rankin JW, Turpyn AD. Low carbohydrate, high fat diet increases C- reactive protein during weight loss. Journal of the American College of Nutrition, 2007, 26(2):163-169.

17. Seshadri $\mathrm{P}$ et al. A randomized study comparing the effects of a low-carbohydrate diet and a conventional diet on lipoprotein subfractions and C-reactive protein levels in patients with severe obesity. American Journal of Medicine, 2004, 117:398-405.

18. King DE et al. Effect of a high-fiber diet vs. a fiber-supplemented diet on C- reactive protein Level. Archives of Internal Medicine, 2007, 167:502-506.

19. North CJ, Venter CS, Jerling JC. The effects of dietary fibre on C-reactive protein, an inflammation marker predicting cardiovascular disease. European Journal of Clinical Nutrition, 2009, 63(8):921-933.

20. Geraldo JM, Alfenas Rde C. Role of diet on chronic inflammation prevention and control - current evidences. Arquivos Brasileiros de Endocrinologia \& Metabologia, 2008, 52(6):951967.

21. Aeberli I et al. Dietary intakes of fat and antioxidant vitamins are predictors of subclinical inflammation in overweight Swiss children. American Journal of Clinical Nutrition, 2006, 84(4):748-755. 
22. Fischer $\mathrm{CP}$ et al. Plasma levels of interleukin-6 and C-reactive protein are associated with physical inactivity independent of obesity. Scandinavian Journal of Medicine and Science in Sports, 2007, 17(5):580-587.

23. Balducci $S$ et al. Anti-inflammatory effect of exercise training in subjects with type 2 diabetes and the metabolic syndrome is dependent on exercise modalities and independent of weight loss. Nutrition, Metabolism \& Cardiovascular Diseases, 2010, 20(8):608-617.

24. Bertrann $\mathrm{N}$ et al. Diet and lifestyle are associated with serum Creactive protein concentrations in a population-based study. Journal of Laboratory and Clinical Medicine, 2005, 145:41-46.

25. Hatunic $M$ et al. Vascular inflammatory markers in early-onset obese and type 2 diabetes subjects before and after three months' aerobic exercise training. Diabetes and Vascular Disease Research, 2007, 4(3):231-234.

26. César-Neto JB et al. Smoking modulates interleukin-6: interleut kin-10 and RANKL: osteoprotegerin ratios in the periodontal tissues. Journal of Periodontal Research, 2007, 42(2):184-191.

27. Ahonen TM et al. Gender difference among smoking, adiponectin, and high-sensitivity $\mathrm{C}$ - reactive protein. American Journal of Preventive Medicine, 2008, 35(6):598-601.

28. Hastie CE, Haw S, Pell JP. Impact of smoking cessation and lifetime exposure on C-reactive protein. Nicotine and Tobacco Research, 2008, 10(4):637-642.

29. Asthana A et al. Effects of smoking intensity and cessation on inflammatory markers in a large cohort of active smokers. American Heart Journal, 2010; 160(3):458-463.

\section{International conference on healthy lifestyles and noncommunicable diseases in the Arab World and Middle East, 10-12 September 2012}

The Ministry of Health of Saudi Arabia, in collaboration with the WHO Regional Office for the Eastern Mediterranean, is organizing an international conference focusing on the implementation of the UN Political Declaration on Noncommunicable Diseases in the Region. Representatives from ministries of health, foreign affairs and planning, the League of Arab States, United Nations funding agencies, programmes and agencies, international financial institutions, development banks and other key international organizations are expected to attend.

The aims of the conference are to:

- review and adopt a set of monitoring indicators for noncommunicable disease surveillance systems

- share strategies, tools and cost-effective interventions that countries in the Region may have implemented in relation to surveillance, prevention and improved health care for noncommunicable diseases

- articulate a road map for capacity-building for the Region based on a review of current regional and national capacities

- discuss and adopt a research agenda concerning noncommunicable disease priority areas in the Region.

Further information about the work of WHO/EMRO with regard to noncommunicable diseases is available at: http:// www.emro.who.int/entity/noncommunicable-diseases/ 